\title{
Brazilian society of cardiac arrhythmias: aiming for profit or saving lives?
}

\author{
Márcio Galindo Kiuchi ${ }^{1,2}$ and Shaojie Chen ${ }^{2}$ \\ ${ }^{1}$ Division of Artificial Cardiac Stimulation, Department of Medicine, Hospital e Clínica São Gonçalo, São Gonçalo, RJ, Brazil \\ ${ }^{2}$ Department of Cardiology, Elisabethinen University Teaching Hospital Linz, Linz, Austria
}

In 2010, the Brazilian Society of Cardiac Arrhythmias (SOBRAC) reported that the National Health Surveillance Agency (ANVISA) determined that reprocessing single-use materials is prohibited in two situations: the first is whether the material listed is published in RE ANVISA No 2605/06 of August 2006. The second is when the product label reads: SINGLE USE - PROHIBITED REPROCESSING, according to RDC ANVISA $n^{\circ} 156$ August 2006. Electrophysiology catheters fall into the second definition. In 2016, after a corruption scandal in Brazil, in which several electrophysiologists were accused by the public ministry of using reprocessed material, the SOBRAC has moved to change its opinion and determination by communicating the following "The SOBRAC, prioritizing patient safety, its broad access to cutting-edge treatments, good medical practices and professional defense, once again disseminate the information necessary to better understand the events that have occurred in recent months. Last week, the presidents of SBC, SOBRAC and a Director of SBHCI, met to discuss the positioning of societies regarding reprocessing of electrophysiology and hemodynamics materials. Taking into account the consequences that hasty decisions could cause, especially for the Single Health Service in Brazil, after a long and friendly discussion, all were favorable to the freedom to carry out the reprocessing. In addition, actions are being carried out in order to adapt information contained in product labels, which may be generating dubious interpretations regarding the materials that can be used in this practice". Recently, Mendes and colleagues published that Literature shows that there is a lack of validated protocols for reprocessed single use device, which includes the cardiac catheters. Most of the studies have not shown a significant difference between the use of a new device and a reprocessed one, although there are some considerations as for the number of cycles of reprocessing, presence of biological waste and potential effect in vivo must be taken to any conclusions. There is a shortage of controlled trials performed in this area, with most of the studies made in an experimental setting. The high cost of the devices and the possibility of reuse, without any damage to the patients, have stimulated many authors to elaborate scientific papers in order to prove the efficacy of reprocessing protocols suggested by them. More studies of higher impact should be performed to answer these issues with safety [1]. Based on this controversial point of views, we used 1,200 catheters in electrophysiological studies (EPS) and ablation procedures. After each procedure, the catheter was sent for two companies to be reprocessed, and when they came back, we sent the tip to culture in a private laboratory.

The results are expressed as a mean and standard deviation for normally distributed data and as median with interquartile range otherwise. All statistical tests were two-sided. Comparisons between two-paired values were performed with the paired t-test in cases of a Gaussian distribution and by the Wilcoxon test otherwise. Categorical variables were compared with Fisher's exact test. A P-value $<0.05$ was considered significant. All statistical analyses were performed using the program GraphPad Prism v 7.0 (GraphPad Software, La Jolla, CA, USA).

At the evaluation of the tip catheters after reprocessing, only 437 (36\%) of the 1,200 presented negative catheter tip culture. And, $763(64 \%)$ of the 1,200 catheter tip culture were positive $(\mathrm{P}<0.0001$; Relative Risk $=1.7,95 \% \mathrm{CI}=1.6$ to 1.9 ; Odds Ratio $=3.0,95 \% \mathrm{CI}=2.6$ to 3.6), as shown in Figure 1. The most common types of bacteria are meticulously displayed in Table 1 . As recommended by manufacturers, we conclude that catheter reprocessing is unsafe because catheter tip cultures were $64 \%$ positive with several types of bacteria isolated. So, Brazilian Society of Cardiac Arrhythmias: aiming for profit or saving lives?

\section{Acknowledgements and funding}

The authors thank all participants of this study and the health insurances from the State of the Rio de Janeiro.

\section{Funding}

The study was sponsored by health insurances in the state of Rio de Janeiro.

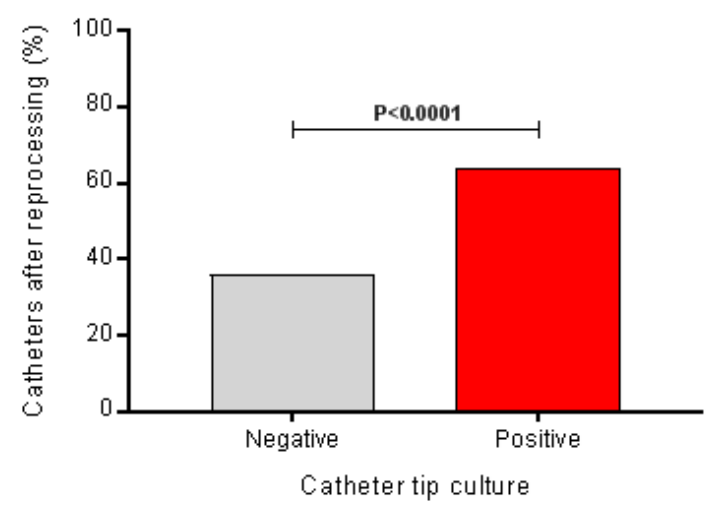

Figure 1: At the evaluation of the tip catheters after reprocessing, only 437 (36\%) of 1,200 presented negative catheter tip culture. And, $763(64 \%)$ of the 1,200 -catheter tip culture were positive $(\mathrm{P}<0.0001)$.

Correspondence to: Márcio Galindo Kiuchi, Division of Artificial Cardiac Stimulation, Department of Medicine, Hospital e Clínica São Gonçalo, Rua Cel. Moreira César, 138 - Centro, São Gonçalo, Rio de Janeiro 24440-400, Brazil, Fax: +55 (21) 26047744; E-mail: marciokiuchi@gmail.com

Received: June 29, 2017; Accepted: July 24, 2017; Published: July 27, 2017 
Table 1. Catheters after reprocessing

\begin{tabular}{|l|l|}
\hline Bacteria & $\begin{array}{l}\text { Catheter tip culture } \\
\text { Positive }\end{array}$ \\
\hline N & $763(64 \%)$ \\
\hline Gram-negative & 104 \\
\hline Pseudomonas aeruginosas & 40 \\
\hline Escherichia coli & 63 \\
\hline Salmonella & 55 \\
\hline Shigella & 68 \\
\hline Acinetobacter baumannii & 15 \\
\hline Serratia spp & 2 \\
\hline Citrobacter spp & 26 \\
\hline Proteus spp & 103 \\
\hline Gram-positive & 3 \\
\hline Staphylococcus aureus & 119 \\
\hline Streptococcus pneumoniae & 104 \\
\hline Streptococcus pyogenes & 2 \\
\hline Enterococcus faecalis & 59 \\
\hline Lactobacillus spp & \\
\hline $\begin{array}{l}\text { Methicillin-resistant Staphylococcus } \\
\text { aureus (MRSA) }\end{array}$ & \\
\hline Values are presented as n. & \\
\hline
\end{tabular}

\section{References}

1. Mendes RRS, Albuquerque GS, Silva RCP, Jesus MNS, Cunha GC, et al. (2011) Reuse of electrophysiology cardiac catheters. Relampa 24 :151-160.

Copyright: $₫ 2017$ Kiuchi MG. This is an open-access article distributed under the terms of the Creative Commons Attribution License, which permits unrestricted use, distribution, and reproduction in any medium, provided the original author and source are credited. 